very large industry. It is not proposed to discuss the two sides of the question-the maintenance of the industry or the pre. servation of the purity of such a fine river as the Spey, or other rivers similarly situated-but rather to consider what can be done to meet both sides. Now it may be held as true that there is no operation to which the burnt ale or spent lees of a distillery can practically be subjected to, that will render the effluent innocuous. The effluent may be evaporated or spread over irrigation fields, or treated with chemicals or charcoal, and yet the processes are in one way or another defective; and there appears but one solution, not to pass the effluent into the rivers, but take it away in pipes or barges to the sea. In many cases this is quite impracticable, even by the joint action of a number of distilleries; but in some cases the effluent has successfully been taken miles in pipes and discharged into the sea. As is known from large experience in outfall pipes for sewage and paper works effluents, it requires a carefully designed arrangement, the cost of which can only be determined after a minute survey ; and usually the cost turns out to be too great, and then there appears to be one solution by passing the effluent out in the form of a fine spray from the top of a high chimney or iron lattice tower. The natural question at once asked is: But you pollute the air instead of the water, and what the better are you for doing so? In the first place, what is discharged is not a gas which, if of a noxious quality, might hurt by being inhaled. It is not like soot, which might leave a black mark on your face or clothes. The spray, if it fell on your skin or clothes, could do you no harm, or at least infinitesimal harm. It is not a poisonous liquid, as cattle can drink it. If it fell on trees or grass, except in large quantities, which would not be the case, it would not burn them. Pollution of air is not objected to unless it be in great excess; indeed, we all pollute the air to our neighbours' and our own disadvantage. We send out gases and smoke from our chimneys, which find their way to our neighbours' carpets and curtains and clothes, and we put out the foulest of gas-viz. sewer gas-daily and hourly from the ventilating pipes of our modern house drains, and many of our factories, electric light stations, \&c., pass out gases which individually one would say would be sufficient to affect a whole city. There are many physical reasons which make the great difference on the harmless nature of air pollution from water pollution, and that is the cubic capacity of the polluted substance.

In the case of air the air stream is measured in cubic miles, whereas the water stream is a matter of cubic feet; again, the water flows in one fixed channel, whereas the wind and air stream is constantly varying; again, water pollution is worst just when it is put into the river, whereas air pollution is spread over a large area and is thoroughly mixed up before it comes down, possibly one mile or two miles from where it issued from the chimney.

Again, it may be said that even supposing the spray be harmless, yet it would be very disagreeable to be subjected to a fine rain or Scotch mist when near the distillery. Let us consider a distillery sending out four gallons per minute. An ordinary noncondensing engine uses $20 \mathrm{lb}$. of water per H.P. per hour, so that the quantity discharged from the top of the chimney is no more than what is sent out from a steam engine (high pressure) of 120 I.H.P., and we know from experience that this can be discharged without being felt, and in most weathers even becoming invisible 100 feet away. If it were practicable to reduce the effluent to a state of fine division as fine as the globules of the so-called white steam, and emit it from the top of a chimney, the solution of the matter would be found at once. It does not at present either appear practicable to reduce the effluent to such a fine state of division, nor fortunately is it necessary to do so, as experiment shows that ordinary sprayed particles are rapidly evaporated and absorbed. Take a spray such as barbers use, and spray it from a height of 5 feet in a still atmosphere, and measure the quantity evaporated in its descent. It will be found that at least $1 / 8$ th has been lost. Do the same at ro feet, and it will be found that $I / 4^{\text {th }}$ is lost. Theory points to very rapid evaporation, as the particles get small as the surface becomes rapidly large in comparison with the cubic capacity of the spheres. Another good example of rapid evaporation and absorption by the air is to use the spray over a piece of glass. In ordinary weather only a very short space of time renders the sheet glass quite dry again. These two experiments, and our experience of the discharge from steam engines pointing to this, that instead of experiencing a mist or fine rain, the particles would be so minute and so wide-

NO. I 50 I, VOL. 58] spread that no one might suffer any inconvenience, indeed might be quite unconscious of the fact that the spraying was going on except from seeing the white steam mist issuing from the chimney of the distillery.

Coming now to a more practical view as to what would be necessary to obtain the desired effect, and trials lead to this, that for a discharge of four gallons per minute it would be necessary to have a pump to pump up this small quantity, also an air pump to pump about forty times the volume liquid, a 5-H.P. oil engine with air pump attached, such as is used in lighthouses for supplying the air blast to fog signals, being ample. The necessary length of pipes leading up to the spraying apparatus with a number of nozzles, and above all a high point of discharge, completes the arrangement.

The height of discharge is evidently one essential of success. The height will vary with the amount of the effluent, and whether the works be situated on a moor, near a town, or in a cleft in the hills, or among high trees.

The increase in the velocity of the wind with height is an important factor. In measuring the velocity at 50 feet, Ioo feet and 200 feet, we find a great increase with height, so that instead of a point of discharge of 200 feet being only capable of doing twice what a height of 100 feet will do, as one might at first suppose, yet a little consideration will show, as the area is a measure of the degree of dispersion, that it will disperse successfully much more. In fact whereas Ioo feet might dis. charge one gallon, 200 feet might discharge eight gallons per minute. It would appear, therefore, that to attempt to deal with the effluent by spraying at a low level, as has been in some quarters suggested, is simply to court failure. The point of discharge must be high, but "how high" is a matter which at present is unknown; nor, indeed, can it be definitely fixed, as has been pointed out, each individual work requiring special consideration of the circumstances. There is one other point that requires to be considered in connection with the whole matter, and that is compensation for water abstraction. At present distillers use the water, and what is not sent off as whisky is returned to the stream. But in the case of carrying the effluent to the sea, compensation would require to be given to the stream by means of reservoirs, and with the spraying apparatus a complicated question would arise as to how much really found its way back into the water-courses of the particular drainage area. This is largely a legal question, but it is not clear how the spraying process could differ from the discharge into the atmosphere of an ordinary steam engine, and so it would appear that water compensation for the stream was with this system unnecessary.

C. A. Stevenson.

\section{The Nature and Habits of Pliny's Solpuga.}

I HAVE never seen one of the Arachnoids in a hive, but have received them several times from trustworthy bee-keepers who have found them in the hives "killing and eating the bees." Other insects do the same thing, especially Formicids and Mutillids. Of course the latter, with more chitine, are better fitted to resist the attack of the bees than are the soft-bodied Datames. It may be that these Solpulgids have some protective scent that makes their entrance to the dark recesses of the hive safe.

Claremont, Cal., June 23.

A. J. C.

\section{THE VACCINATION BILL.}

$\mathrm{I}$ connection with the recent discussion on the vaccination question, nothing strikes the inquiring observer more than the shortness of the collective memory or a people, unless, indeed, it be the fact that people are easily led by any small knot of agitators who will shout loudly enough and asseverate with sufficient force and frequency.

That this is true not only of what may be called the masses, but also of their selected representatives in the House of Commons, is evident from what has recently transpired in that august assembly. The career of the Vaccination Bill has been marked by many stormy passages and by very varying fortunes, and now that it has passed through its first stage, there appear to be few who are even partially satisfied. This is a result 